\title{
GIS analysis of promising landing sites for manned flight to Mars
}

\author{
Marina Kuziakina ${ }^{1, *}$, Dmitry Gura ${ }^{2,3}$, and Dmitry Zverok ${ }^{1,2}$ \\ ${ }^{1}$ Kuban state university, Krasnodar, Russia \\ ${ }^{2}$ Kuban state technological University, Krasnodar, Russia \\ ${ }^{3}$ Kuban state agrarian University, Krasnodar, Russia
}

\begin{abstract}
Remote sensing provides data that can be used in a variety of projects. One such project is the preparation for sending a manned flight to Mars. Before the departure of the expedition it is very important to carefully select a place of high scientific value and a high security level for the members of the flight. Remote sensing methods allow getting the whole set of necessary data, which will later be used for the flight equipment properly, as well as to adapt the lander design. Currently, robotic probes that send the collected information to Earth are engaged in the collection of the necessary data. There, the data, in turn, can be processed by specialists, as well as provided for the general public for informational purposes only.
\end{abstract}

\section{Introduction}

The inhabitants of the Earth receive the necessary information about Mars by using probes. They are a more effective instrument for remote sensing compared with telescopes of various fractions, since they can work in close proximity and even at the site itself.

The data obtained using the following devices were selected for the analysis: Orbital probes (Automatic Interplanetary Stations - AIS): "MAVEN", "Mars Global Surveyor", "Mars Reconnaissance Orbiter", "Mangalyaan", "Mariner-9", "Mars Odyssey", "Mars Express", "Trace Gas Orbiter". Ground probes: Stationary Automatic Martian Stations (AMS): "Vicking-1", "Viking-2", "Mars Pathfinder", "Phoenix". And mobile Rovers: "Spirit", "Opportunity", "Curiosity" [1,2].

It is assumed that the Mars Odyssey and MRO spacecrafts will be sent to the optimal landing sites after determining their location $[3,4]$. With their help, a thorough study of the presumptive landing sites will be carried out, and their detailed maps will be created.

In [5], an overview of manned flight projects to Mars is presented. There is an acute problem of finding places for the safe landing of a manned flight on its surface [6]. For example, in SpaceX [7], nine places are proposed as possible landing sites, which have the following disadvantages: insufficiently warm, flat, and safe. Among the many proposed places, the most optimal are: Acidalia Planitia (1), Schiaparelli Crater (2), Elysium Planum

\footnotetext{
* Corresponding author: gda-kuban@mail.ru
} 
(3), Hellas Plain (4) (the numbers represent the numbers of the places on the maps below). The 4 places selected by the authors are marked with rectangles with assigned numbers and are shown in Figure 1, which is a topographic map of Mars obtained by the MGS apparatus using the MOLA laser altimeter [8].

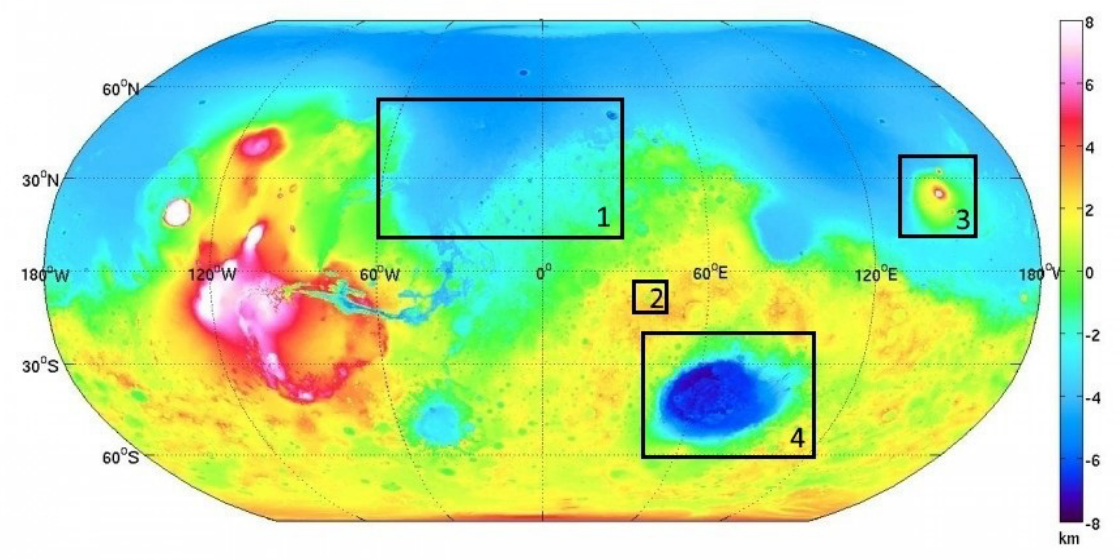

Fig. 1 The topographic map of Mars surface of with the alleged presumptive landing sites marked on it. Source: http://www.asu.cas.cz

\section{Materials and methods}

Presumptive areas meet many of the selection criteria and have sufficiently even ground for a safe landing. It is difficult to select one of them, since each has its own advantages and disadvantages.

The following maps were used for analyzing the places selected by authors: a series of topographic maps, a map of gravitational anomalies, a map of surface magnetism, an equivalent dose map, a map of volcanoes, day and night temperature maps, and a fast neutron emission map. Maps were obtained based on data collected by probes. Based on these maps, information about the average values of various indicators in the marked places was obtained, which was later used to directly analyze these places for their suitability for the expedition.

A team of authors selected one of the main (most significant) indicators for preliminary analysis. In fact, a much wider range of parameters will be taken into account before sending the expedition itself.

The following indicators are the most significant for selecting a landing site for an expedition: gravitational anomaly; relief affecting landing difficulty; magnetic field strength; absorbed radiation; rock composition; the presence of volcanoes; daytime temperature; night temperature; the presence of water.

Gravitational anomaly is a general term that is used in cases when unusual indicators of the gravitational field or the unusual gravitational characteristics of an object are observed. A map of the gravitational anomalies of Mars is presented in Figure 2, which shows that the average value of the gravitational anomalies in the vicinity of the Acidalia Planitia is about $-60 \mathrm{mGal}$; for Schiaparelli Crater it is about $75 \mathrm{mGal}$; for Elysium Planum it is about 250 $\mathrm{mGal}$; about $50 \mathrm{mGal}$ for Hellas Plain [4, 9]. Consequently, the Acidalia Planitia shows the best result, and the Elysium Planum shows the worst.

A map of volcanoes located on the surface of Mars is presented in Figure 3, which shows that they are only located on the Elysium Planum and absent in other locations [10]. 
The presence of volcanoes near the planned landing site of a manned flight has a negative effect.

A magnetism map of the surface of Mars is shown in Figure 4. It shows that the average magnetic fields are observed in the region of Acidalia Planitia, the Elysium Planum and the Hellas Plain, and in the region of the Schiaparelli Crater these indicators are slightly lower [11]. Therefore, according to the results of measuring the magnetic field strength, the best location for landing is the Skiparelli Crater.
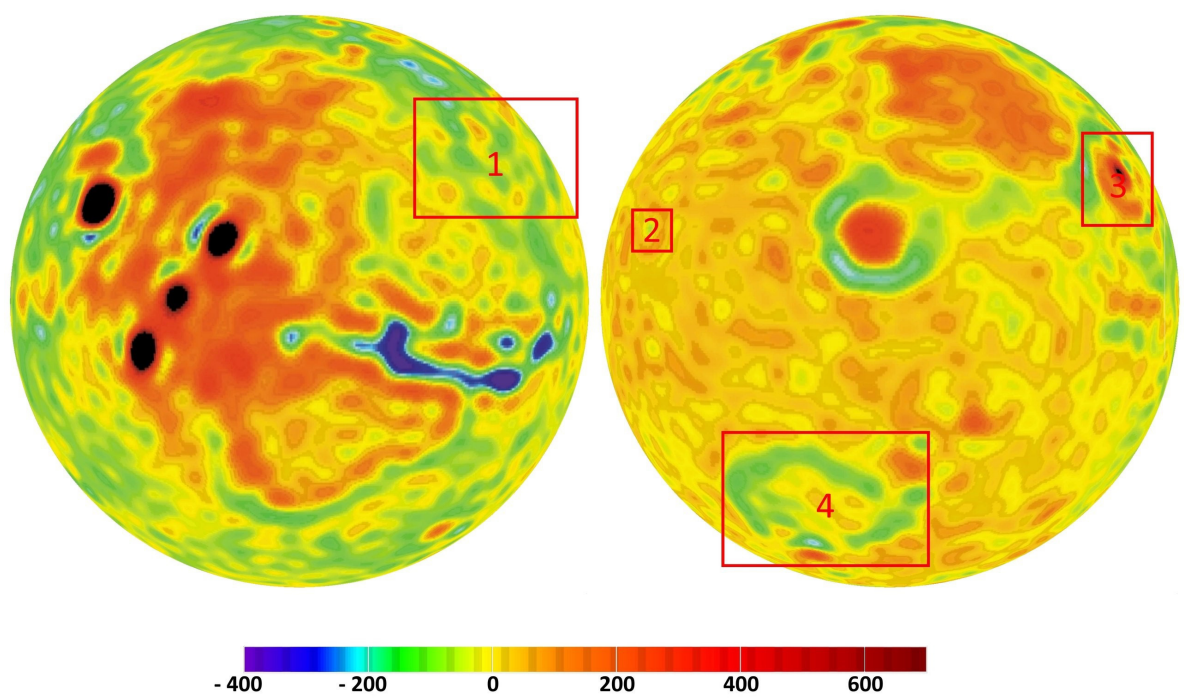

Fig. 2. Map of the gravitational anomalies of Mars, mGal. Source: http://mars.jpl.nasa.gov

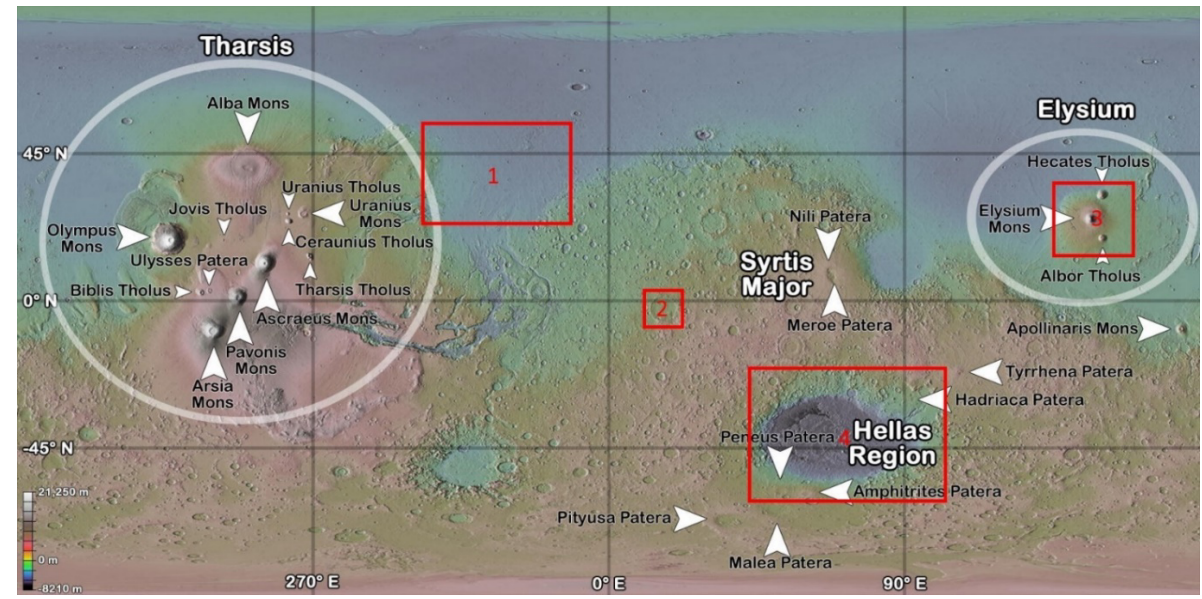

Fig. 3. Mars Volcanoes Map. Source: https://spacegid.com 


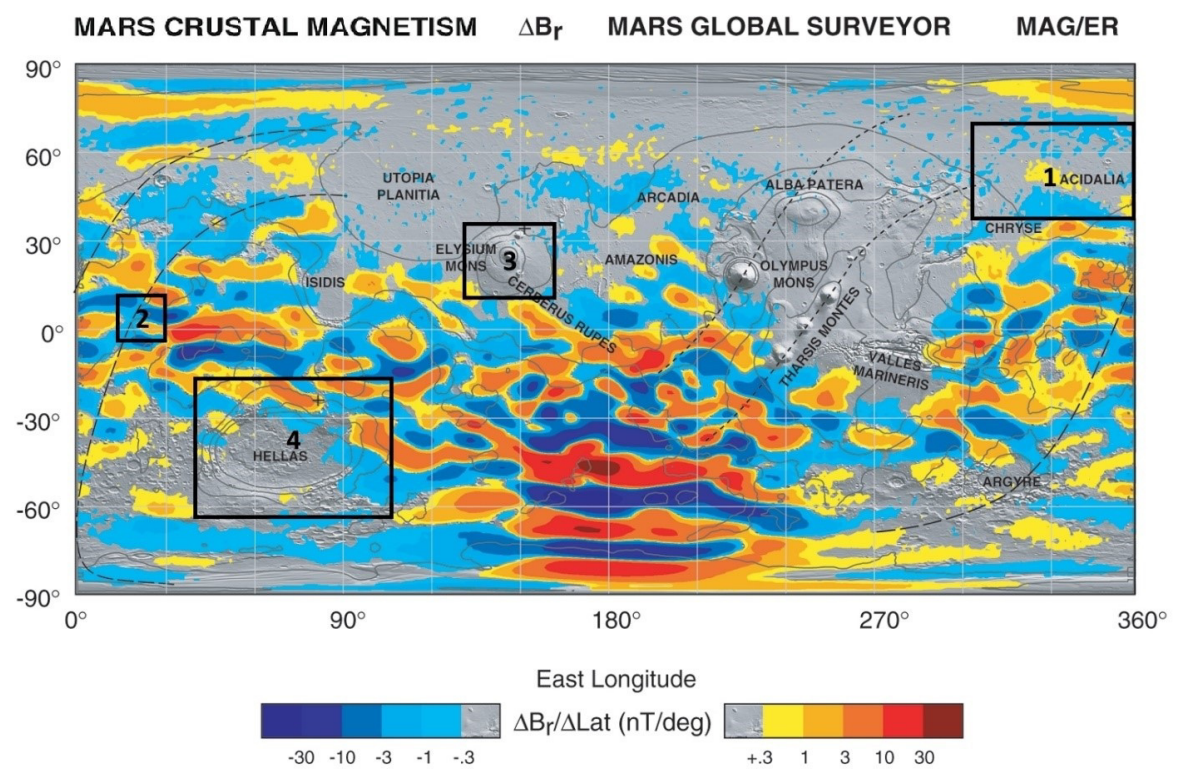

Fig. 4. Magnetism Map of the Mars surface. Source: http://www.nasa.gov

An equivalent dose is a dose of radiation absorbed by living tissue multiplied by a coefficient $\mathrm{k}$, which takes into account the danger degree of various radiation types. In the SI system, Sievert (Sv) is used to measure the equivalent dose. Non-systemic unit of equivalent dose used is Rem (rem): $1 \mathrm{~Sv}=100 \mathrm{rem}$. Generally speaking, the permissible level of radiation for a person from natural sources of radiation is $0.5 \mathrm{rem} / \mathrm{year}$.

A map of the equivalent radiation dose values absorbed by the surface of Mars is presented in Figure 5, which shows that the average value of the equivalent dose in the vicinity of the Acidalia Planitia is about $13 \mathrm{rem} / \mathrm{year}$; for Schiaparelli Crater it is about 18 rem/year; for the Elysium Planum it is about 17 rem/year; for the Hellas Plain it is about 10 rem/year [12]. Thus, it is conditionally assumed that the Hellas Plain is the most favorable option.

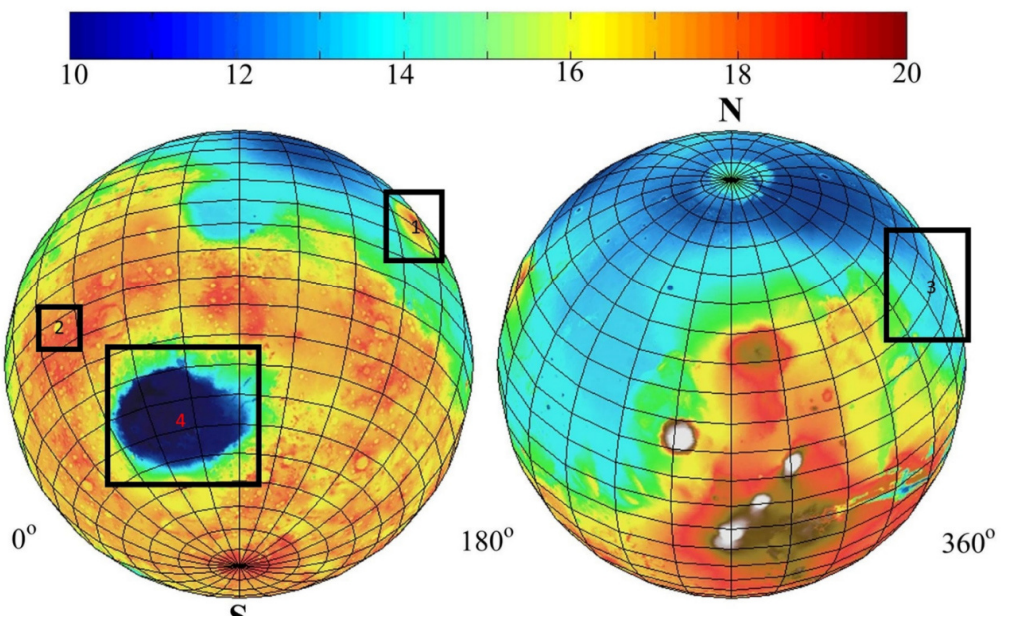

Fig. 5. Map of the equivalent dose values of the Mars surface, rem/year. Source: https://phys.org 
A map of the daily temperature of the Mars surface is presented in Figure 6, which shows that the average daytime temperature in the vicinity of the Acidalia Planitia is about $17{ }^{\circ} \mathrm{C}$; for Schiaparelli Crater it is about $2{ }^{\circ} \mathrm{C}$; for Elysium Planum it is about $6{ }^{\circ} \mathrm{C}$; for Hellas Plain it is around $-98{ }^{\circ} \mathrm{C}$ [10]. Hellas Plain shows the worst result. However, you cannot analyze daytime temperatures without taking into account nighttime temperatures.
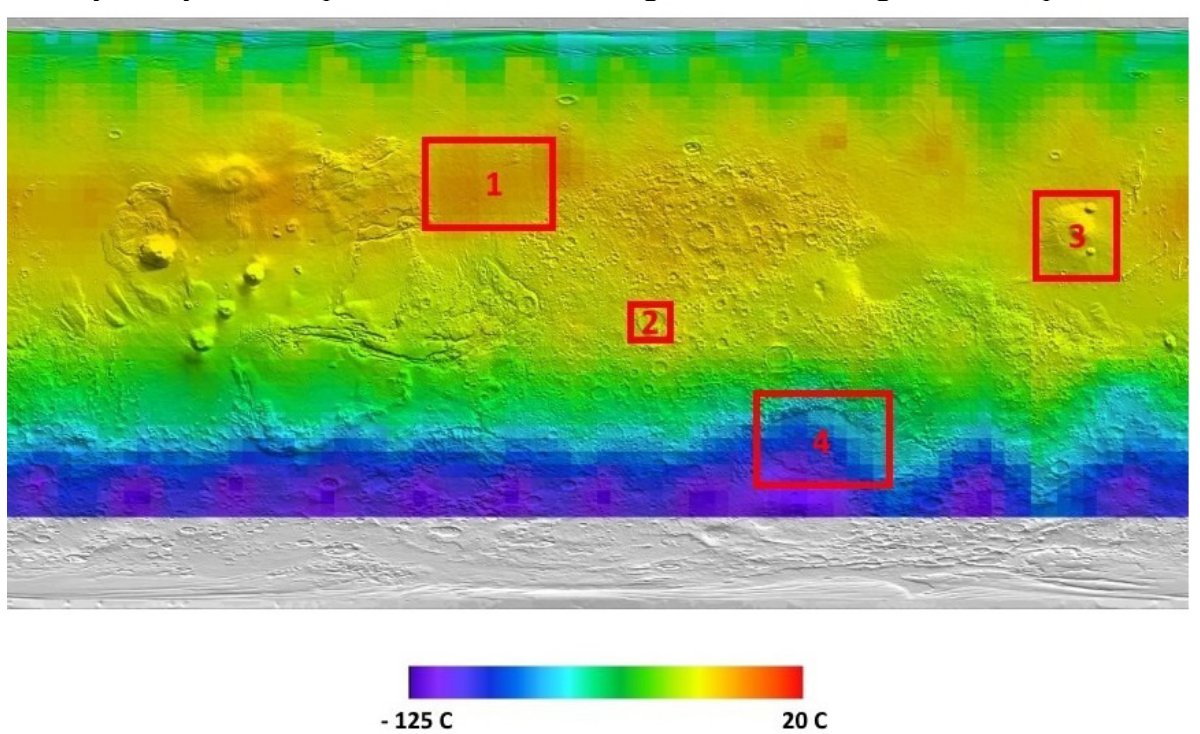

Fig. 6. Daily temperature map of the Mars surface. Source: https://spacegid.com

A night temperature map of the Mars surface is presented in Figure 7, it shows that the average temperature at night in the vicinity of the Acidalia Planitia is about $-40{ }^{\circ} \mathrm{C}$; for Schiaparelli crater it is about $-110{ }^{\circ} \mathrm{C}$; for Elysium Planum it is about $-80{ }^{\circ} \mathrm{C}$; for Hellas Plain it is around $-115^{\circ} \mathrm{C}[10]$. The best result is shown by the Acidalia Planitia.

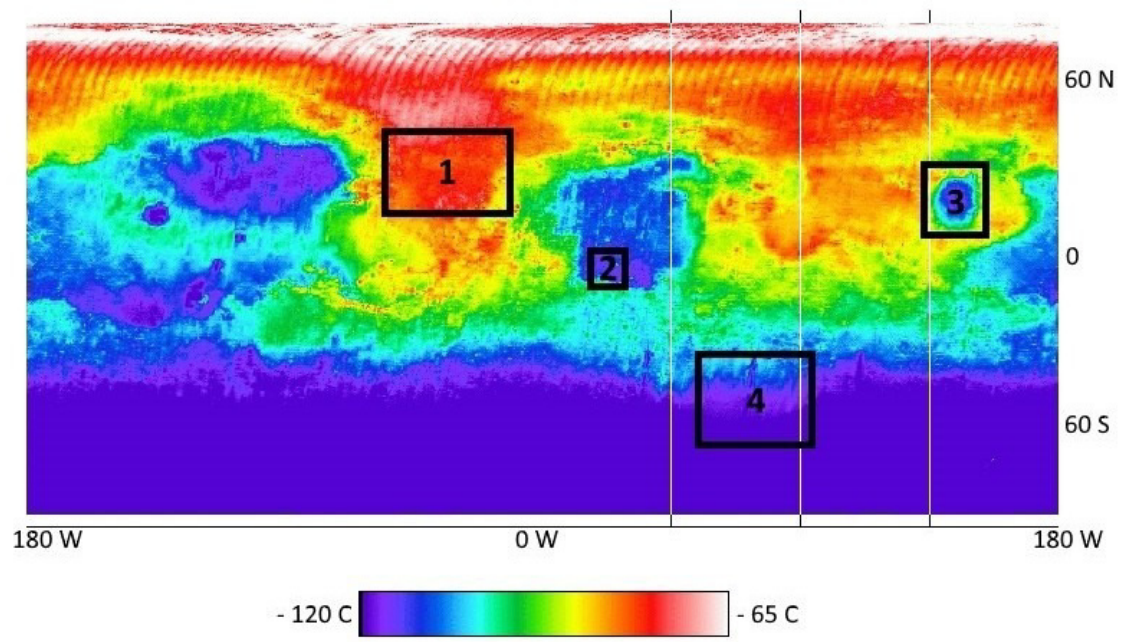

Fig. 7. Night temperature map of the Mars surface. Source: https://spacegid.com 
The hydrosphere of Mars is represented by water ice in polar caps and ice above the surface in the atmosphere, due to the prevailing low temperatures. Only due to the presence of water on the surface, Mars entered the manned flight program.

A water content map on the Mars surface is presented in Figure 8, which shows that the average value of the water content in the vicinity of the Acidalia Planitia is about 3\%; for Schiaparelli Crater it is about 7\%; about 6\% for Elysium Planum; about 3\% for Hellas Plain $[11,13]$. Also, the presence of water on the surface of Mars is confirmed by data obtained from ground-based probes.

A neutron map of the Mars surface is presented in Figure 9, it is obtained by neutron spectroscopy, which also indicates the presence of water on Mars. Regions with a low neutron emission index indicate the presence of a high concentration of hydrogen, which is a water component [11]. Also, the composition of the surface layers of Martian soil can be determined according to this map, that is the composition of the rocks [14].

The neutron spectroscopy method is a nuclear method for studying the surface composition of planets, which provides reliable information on the chemical composition of the surface (at a depth of 1-2 m) soil layers. The gamma and neutron radiation of planets with thin atmospheres (or without atmospheres) can be detected by gamma spectrometers and neutron detectors on orbiting spacecraft. Depending on the duration of the mission and the height of the spacecraft orbit, it is possible to build global maps of neutron radiation of the entire planet or to measure the neutron flux coming from individual sections of its surface $[4,11,15]$.

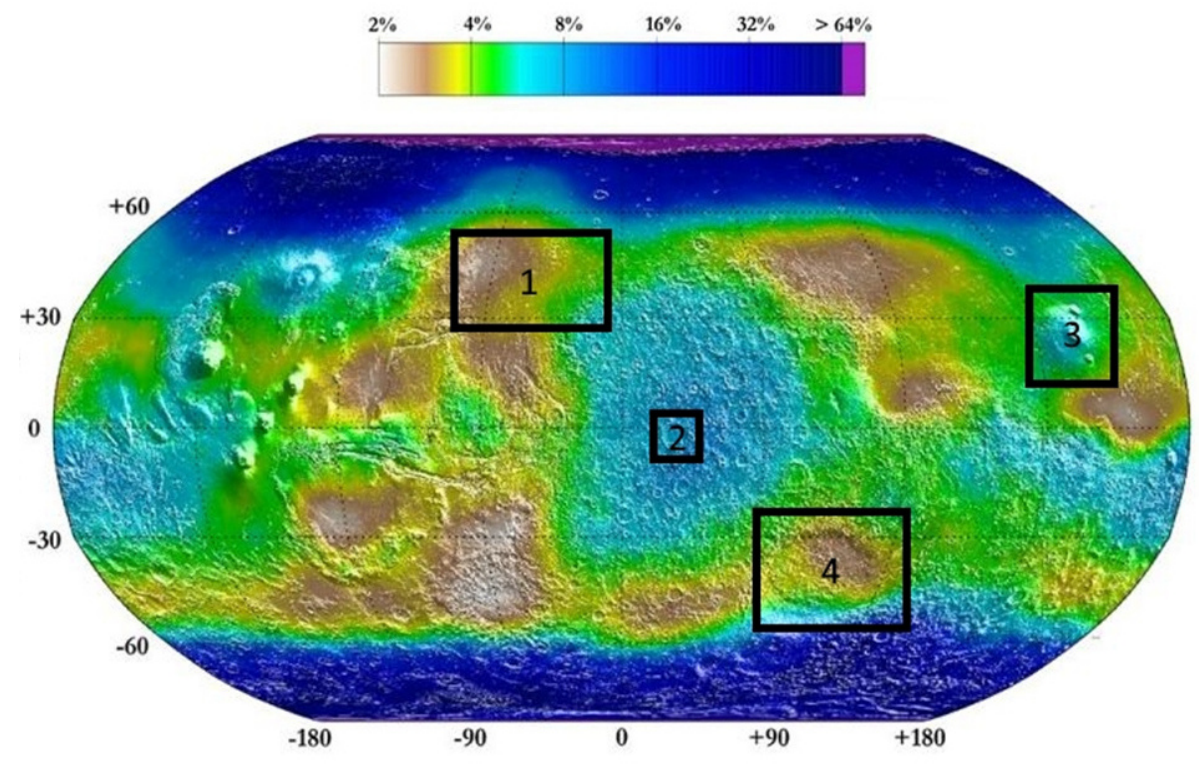

Fig. 8. Map of water content on the surface of Mars. Source: http://www.nasa.gov 


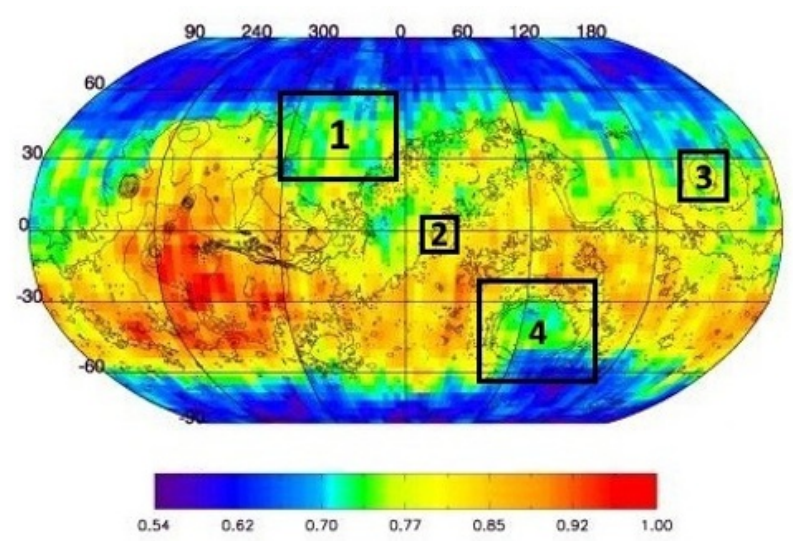

Fig. 9. Neutron radiation map of the Mars surface, compiled by the HEND instrument installed on the Mars Odyssey apparatus, neutrons/sec. Source: http://www.nasa.gov

\section{Results}

The maps presented above provide the necessary information for equipping the expedition, since they display some of the main parameters taken into account when preparing the dispatch of the expedition. Data obtaing from maps with equivalent dose values and maps with night and day temperature will help in developing a lightweight spacesuit to work on Mars. A number of topographic maps, as well as a map of gravitational anomalies and a map of surface magnetism will help to correctly design the landing module, as well as to select a site with high scientific value. Whereas a map of the water content on the surface of Mars will help to calculate the required amount of water for expedition members to take. It is possible that the expedition members will extract water from the environment on Mars.

An analysis of the proposed landing sites was carried out based on these maps. The impact of average indicators on the expedition and its results was determined after analyzing the indicators. After that, a rating scale was compiled, which shows the kind of effect (positive or negative) that one or another parameter will cause during the expedition. A sharp positive effect was graded as 2 points, positive effect had 1 point, moderate -0 , a negative one was graded as minus 1 point, a sharply negative effect as minus 2 points.

After the grading, the scores for each parameter were summed up determining the resulting rating. The results are presented in Table 1.

Table 1. Rating of the indicators.

\begin{tabular}{|c|c|c|c|c|c|}
\hline No. & Indicator & $\begin{array}{c}\text { Acidalia } \\
\text { Planitia }\end{array}$ & $\begin{array}{c}\text { Schiaparelli } \\
\text { Crater }\end{array}$ & $\begin{array}{c}\text { Elysium } \\
\text { Planum }\end{array}$ & $\begin{array}{c}\text { Hellas } \\
\text { Plain }\end{array}$ \\
\hline 1 & Relief (impact on landing difficulty) & 2 & 1 & 0 & -2 \\
\hline 2 & Gravity anomalies & 2 & 0 & -2 & 1 \\
\hline 3 & Magnetic field strength & 1 & 2 & 0 & 0 \\
\hline 4 & Absorbed radiation & 1 & -1 & -2 & 2 \\
\hline 5 & Rock composition & 1 & -1 & 0 & 2 \\
\hline 6 & The presence of volcanoes & -2 & -2 & 2 & -2 \\
\hline 7 & Daytime temperature & 2 & 1 & 1 & -2 \\
\hline 8 & Night temperature & 1 & -2 & -2 & -2 \\
\hline 9 & Water & 0 & 2 & 2 & 0 \\
\hline & TOTAL & 8 & 0 & -1 & -3 \\
\hline
\end{tabular}


First of all, it needs to be noted that the priority in selecting the optimal landing site for the research mission will be given to sites with high scientific value, in addition to the ship landing convenience. The availability of required natural resources that participants of the Mars exploration program can use to live on an alien planet will be also taken into account.

\section{Conclusions}

According to the indicators, it can be seen that the most optimal place based on the set of selected indicators for assessing the expedition landing is the Acidalia Planitia, which scored 8 out of 18 possible points. Consequently, the work of the expedition on it will be safer and more productive.

\section{References}

1. R.E. Arvidson, P. DeGrosse, et al., J. of Terramechanics, 73, 73-93, ISSN 0022-4898 (2017) https://doi.org/10.1016/j.jterra.2017.03.001.

2. M. Vals, A. Spiga, F. Forget, E. Millour, L. Montabone, Planetary and Space Science, 178, ISSN 0032-0633 (2019) https://doi.org/10.1016/j.pss.2019.104708.

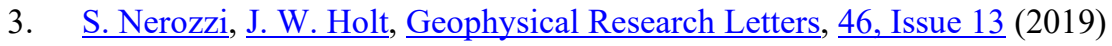
https://doi.org/10.1029/2019GL082114

4. Official website mission MRO, NASA. Available at: http://mars.jpl.nasa.gov

5. B. A. Cantor, N.B. Pickett, M.C. Malin, S. W. Lee, M. J. Wolff, M. A. Caplinger, Icarus, 321, 161-170, ISSN 0019-1035 (2019) https://doi.org/10.1016/j.icarus.2018.10.005.

6. Official website of Lunar and Planetary Laboratory HIRISE Available at: https://www.uahirise.org

7. Official website of Astronomical Institute of the Czech Academy of Sciences http://www.asu.cas.cz/ bezdek/vyzkum/rotating_3d_globe/index.php

A. Genova, S. Goossens, et al., Icarus, 272, 228-245 (2016) ISSN 0019-1035, https://doi.org/10.1016/j.icarus.2016.02.050.

8. Astronomicheskii resurs «Gid v mire kosmosa» https://spacegid.com

9. The official website of NASA Available at: http://www.nasa.gov

10. Estestvennonauchnyi resurs «Phys.org» https://phys.org

11. Alain S.J. Khayat, Michael D. Smith, Scott D. Guzewich, Icarus, 321, 722-735, ISSN 0019-1035 (2019) https://doi.org/10.1016/j.icarus.2018.12.024.

12. Yansong Xue, Yi Yang, Le Yu, Planetary and Space Science, 163, pp. 97-105, ISSN 0032-0633 (2018) https://doi.org/10.1016/j.pss.2017.12.007.

13. MAVEN Science Community Workshop. Available at: http://lasp.colorado.edu/home/maven/2012/12/10/maven-science-communityworkshop/ 